\title{
Modelling a timing belt pitch
}

\author{
Grzegorz Domek ${ }^{1, *}$, and Michat Wilczyński ${ }^{2}$ \\ ${ }^{1}$ Kazimierz Wielki University in Bydgoszcz, Poland \\ ${ }^{2}$ Wilhelm Herm. Muller Polska Sp. z o.o., Poland
}

\begin{abstract}
The paper deals with the problem of timing belt pitch significance for the dynamics of a timing belt transmission gear motion. Specific pitches of timing belts have been used for many years. They were previously reserved for belts made of rubber, while another group of pitches was intended for belts made of polyurethane. This division ceased to apply recently, and in addition there are belts with pitches which have not been used before, such as HTD9M or AT15. The paper presents the parameter that makes the pulley diameter and the pitch dependent on the number of teeth involved in meshing (coupling) with a pulley. It is an equivalent of the coverage factor occurring in cylindrical timing gears. Earlier studies on that parameter did not take into account the teeth unevenly spaced over the width of the belt. New pitches of belts may occur in "mass production" applications and they are applied more and more often. Thus it is important to bear in mind the consequences of changing the pitch of the timing belt in transmission gear structures.
\end{abstract}

Keywords: timing belt, belt pitch, coverage factor

\section{The construction of the timing belt}

The beginnings of timing belts development in the last century were rich in structural and material solutions $[1,2]$. Consecutive types of timing belts were characterized by different geometrical dimensions expressed in inches, as first synchronous belts were developed in the USA at UNIROYAL company. Those solutions were characterized by randomness. Trapezoidal shape of teeth was adopted, however, its size, pitch or the width of the belt were selected depending on the random parameters, such as the amount of space in which the gear could be mounted. First timing belts were intended to replace chains in structures, in order to reduce noise, but unfortunately they turned out to be much less durable. In the search for suitable materials, designers proposed belts made of a steel band. Attempts were made in Germany to make synchronous belts of thermosetting polyurethane. As subsequent materials had been proposed, it was necessary to search for appropriate technologies and design methodologies for subsequent belts.

\footnotetext{
${ }^{*}$ Corresponding author: gdomek@ukw.edu.pl

Reviewers: Tomasz Domański, Darina Ondrušová
} 


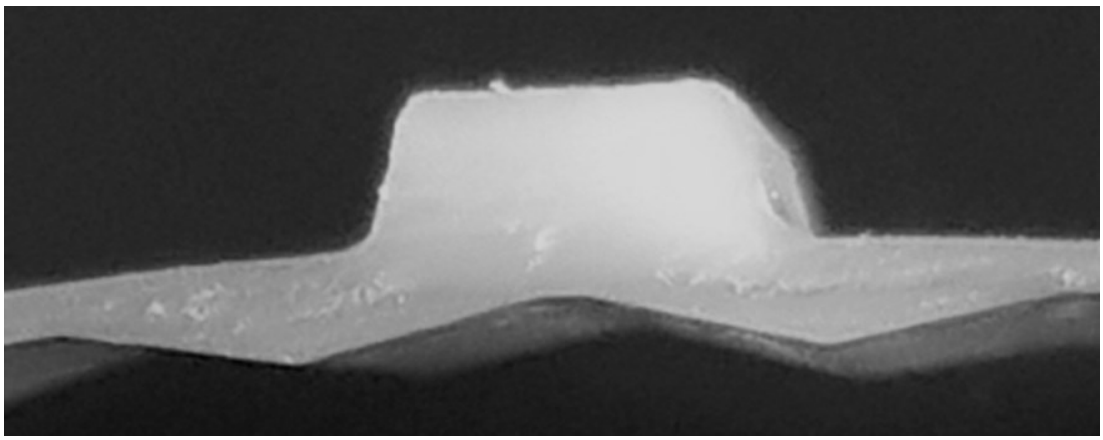

Fig. 1. The picture of a belt cast in the mould with the belt back facing the core

Intense development of timing belts applications prompts manufacturers to make attempts to design "special" belts for "individual" application in the system, which are manufactured in mass production [3, 4]. This allows the manufacturer to be granted exclusive rights for the supply of spare parts. In response to the dynamic development of timing belts applications in bicycle transmissions, one of the leading manufacturers proposed an untypical pitch of $9 \mathrm{~mm}$ (Fig. 2). This was explained by the possibility of optimizing the pitch for products manufactured in large quantities. This opens a discussion on the modelling of the geometric form of a timing belt and the significance of the pitch for the properties of the synchronous transmission gear $[5,6]$.

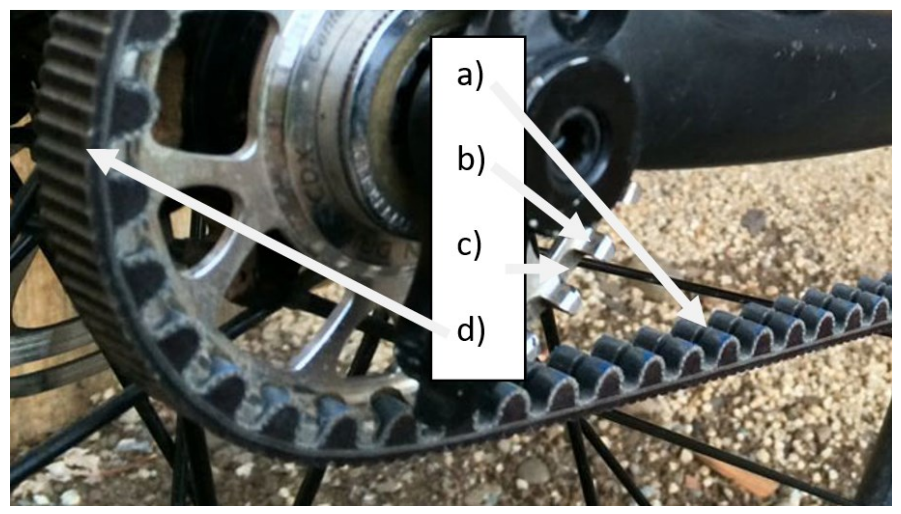

Fig. 2. Belt in the bicycle transmission: a) guide slot, b) pulley teeth, c) guide edge, d) ribbing reducing the tension member stiffness

\section{Belt design methods}

A natural approach to designing synchronous belt transmission gears was a comparison to cylindrical or planetary timing gears, etc. The core of the mould was designed this way and a timing belt was moulded or vulcanised in that mould. Placing a load-carrying layer inside the belt in the right position also posed a manufacturing problem. In the first technological solutions belt teeth were formed above the load-carrying layer (in the body), while only in subsequent solutions they were formed at the core (Fig.1). Thus the belts designed this way differed in lengths and pitches. The methodology of designing the mould core as a pulley of a specific tooth module pitch caused creation of hundreds of belts differing in geometry. It was necessary to individually design the pulleys for each of these belts [7-9]. 
The breakthrough in the timing belts manufacturing technology was a focus on the fact that the kinematics of the transmission gear must be related to the dimension that does not undergo larger distortions during belt operation, i.e. the neutral axis of the load-bearing layer [10-12]. In this case, one of the main properties of the belt is the pitch measured at the level of the neutral axis of the belt load-carrying layer and this also applies to the pulleys. The tooth form remained trapezoidal, and the size of a tooth was assumed to be similar to the size of the tooth space. In order to improve the meshing process with the pulley, the tooth sides opening angle has been reduced [13]. It was found for later structures of belts that their teeth may be larger than the teeth of the pulley due to the lower durability of belts, hence smaller teeth spaces in a belt were used. Basic pitches of belts made of PU were assumed as 2.5, 5, 10 and $20 \mathrm{~mm}$, while for those made of chloroprene as 3, 5, 8, 14 and 20 $\mathrm{mm}$. Geometry of belts with different pitches was proportional to the pitch, which greatly simplified the structural analysis.

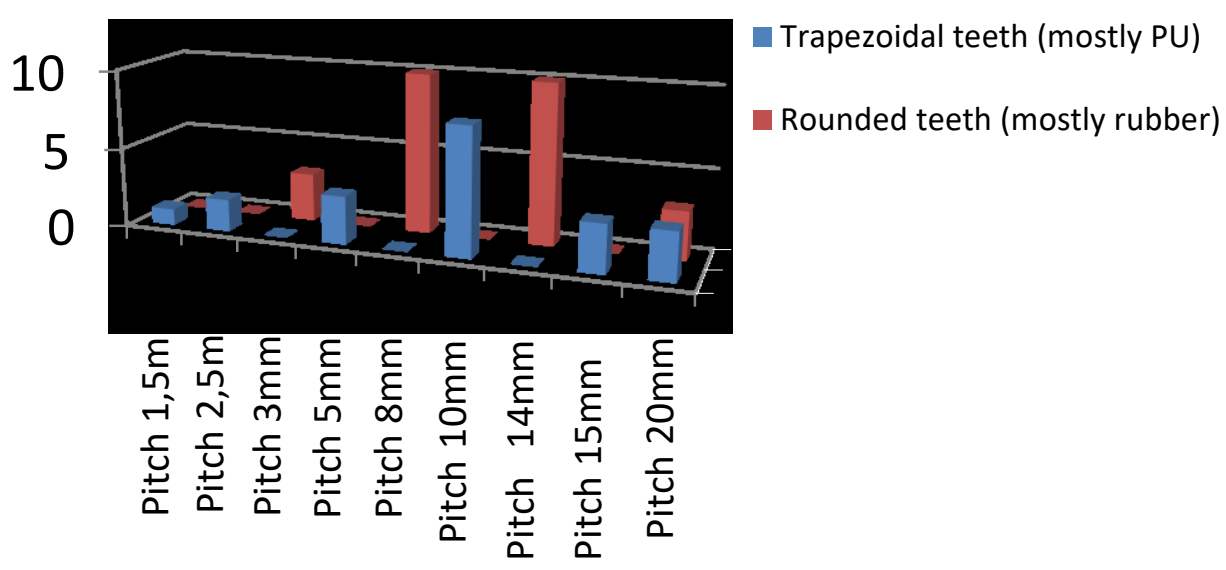

Fig. 3. Typical pitches of timing belts

In the subsequent stages of the new belt structures development, designers focused on the shape of the belt tooth, on the location of the belt tooth within its width, and in recent years, special attention was paid to modern materials used in production, such as the CARBON type cord [14-16].

\section{Modelling a timing belt pitch}

The pitch of the timing belt $(\mathrm{P})$ should be selected so that as many teeth of the timing belt as possible are involved in the meshing with the pulley. For the majority of timing belts, it is assumed that the number of teeth participating in the coupling (meshing) should range from $t_{s}=12$ to $t_{s}=16$. The selection of the pitch from the existing group (Fig. 3) depends on the number of transmission gears that we intend to produce. In large-series projects, such as servo drives in motor vehicles or bike belts, it is possible to model an appropriate pitch of a belt. When performing this task, we begin with the geometric dimensions of the pulleys. The diameters of the pulleys $\left(D_{1}, D_{2}\right)$ determine the pitch (there should be at least 10 teeth at the contact arc). Assuming the pulley contact angle of around $180^{\circ}$ we can assume for the following formula for the first pulley: $t_{l}=2 \cdot t_{s I}$. If the pulley circumference is noted as the product of the number of teeth and the pitch: 


$$
D_{1}=\frac{P \cdot t_{1}}{\pi}
$$

then the pitch:

$$
P=\frac{D_{1} \cdot \pi}{t_{1}}
$$

The width of the pulleys $\left(\mathrm{W}_{1}, \mathrm{~W}_{2}\right)$ determines the materials used in the belt (cord, polymer, fabric coating of the teeth). Torque and pulley rotational speed are input data for the modelling, the same as the geometrical dimensions. In the next step, it should be considered whether the designed transmission gear is of drive, control or conveying nature. Large-series manufacturing is most often dedicated to drive gears, which are characterized by lower belt displacement accuracy due to the clearance that occurs between the belt teeth and the pulley teeth $(\Delta L)$ (Fig. 4).

a)

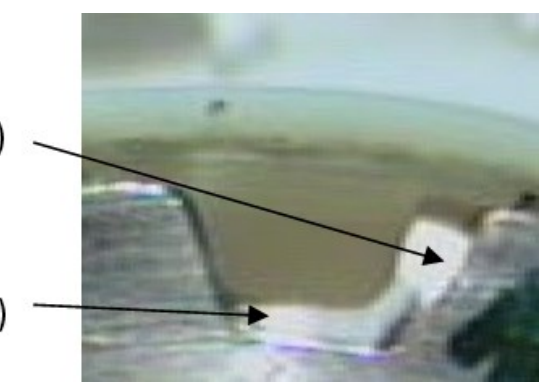

Fig. 4. The clearance between the teeth: a) side play, b) tip clearance

The relative strain $\varepsilon$ of the tension member should not exceed the relative strain of a single pitch $\varepsilon_{P}$ of a belt and should fall into the range of the clearance between the teeth (of a belt and a pulley).

$$
\varepsilon_{P}=\frac{\Delta L}{P}
$$

Active tension member length on the contact arc:

$$
l_{o}=t_{s} \cdot P
$$

whereas the absolute strain is equal to the sum of strains of individual belt pitches on the contact arc and depends on the mechanical properties of the belt.

$$
\Delta l o=\frac{l o \cdot F_{0}}{W_{C} \cdot E}=\sum_{t=1}^{t_{s}} \Delta L_{P}=\Delta l a-\Delta l p
$$

If the circumferential force $F_{o}$ and the geometrical dimensions of the transmission (pulley diameter $D$ and belt width $W_{C}$ ) are determined, then it is only necessary to select a belt of appropriate properties of the load-carrying layer $(E$, assuming that the mechanical properties of a belt tension member within limited strain are of elastic nature) or to select a special cord for the production. In the case of belt pitch modelling, one can make choice from among the available geometric forms of teeth. They are of minor importance. The nature of belt and pulley meshing is more important. Tooth tips of a belt must rest on the bottom of the pulley teeth spaces (grooves). 


\section{Conclusions}

Studies on the teeth strain on the contact arc of the belt clearly show the change in the size of the clearance between the teeth depending on the order of the teeth meshing (Fig. 5). Modelling of a proper pitch favours optimization of the structure and, in combination with the selection of appropriate materials, contributes to improved durability of the entire transmission gear.

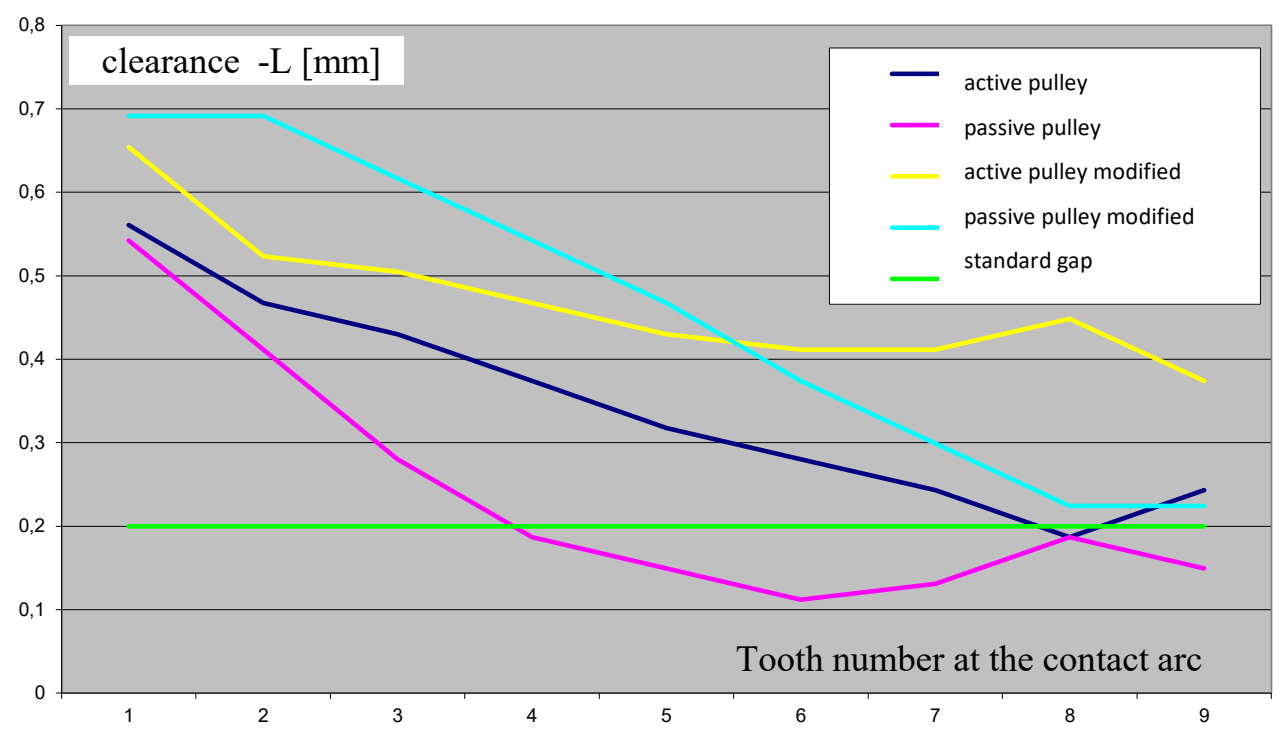

Fig. 5. Clearance between the teeth depending on the order of the teeth meshing

\section{References}

1. L. Jakubovičová, A. Gašparec, P. Kopas, M. Sága, Optimization of the induction heating process in order to achieve uniform surface temperature. Procedia Engineering 136, 125-131 (2016)

2. L. Jakubovičová, M. Sága, Computational analysis of contact stress distribution in the case of mutual stewing of roller bearing rings. Novel Trends in Production Devices and Systems, Applied Mechanics and Materials 474, 363-368 (2014)

3. G. Domek, A. Kołodziej, Design of the tendon structure in timing belts, Procedia Engineering - 2016, Vol. 136, pp. 365-369 (2016)

4. G. Domek, A. Kołodziej, T. Woźniak, R. Kwiatkowski, The Effect of the Pulley Quality on the Accuracy of the Timing Belt Movement, Transport Means 2016 : Proceedings of the 20th International Scientific Conference, October 5-7, 2016, Kaunas University of Technology, Juodkrante, Lithuania - 2016, Part 2, s. 420-423. (2016)

5. G. Domek, A.Kołodziej, M. Dudziak, T.Woźniak, Identification of the quality of timing belt pulleys, Procedia Engineering - 2017, Vol. 177, pp. 275-280. (2018)

6. G. Domek, A. Kołodziej, M.Wilczyński, P.Krawiec, The problem of cooperation of a flat belts with elements of mechatronic systems 55th International Scientific Conference on Experimental Stress Analysis 2017 - EAN 2017, May 30th - June 1st, 
2017, Nový Smokovec, Slovakia. Book of abstracts / red. T. Kula, P. Frankovsky, R. Hunady, J. Bocko, F. Trebuna, J. Kostka.Technical University of Kosice, (2017)

7. G. Domek, M. Dudziak, A. Kołodziej, Description of Timing Belt Coupling Using a Pendulum with Variable Coupling Point, Advanced Technologies in Mechanics - 2015, Vol. 2, nr 1 (2), pp. 1-8. (2015)

8. G. Domek, A. Kołodziej, Modification of Joints in Polymer Timing Belts, Machine Dynamics Research - 2015, Vol. 39, no 1, pp. 15-20. (2015)

9. M. Dudziak, G. Domek, A. Kołodziej, K. Talaśka, Contact Problems Between the Hub and the Shaft with a Four-Angular Shape of Cross-Section for Different Angular Positions, Applied Mechanics and Materials - 2015, Vol. 816, pp. 54-62. (2015)

10. Z. Mičicová, M. Pajtášová, S. Domčeková, D. Ondrušová, L. Raník, T. Liptáková, Inorganic materials and their use in polymeric materials. Procedia Engineering 136, 239-244 (2016)

11. D. Ondrušová, S. Domčeková, M. Pajtášová, A. Dubec, Z. Mičicová, B. Pecušová, Alternative filler based on the waste from glass production and its effect on the rubber properties. Procedia Engineering 177, $462-469$ (2017)

12. M. Sága, P. Kopas, M. Uhríčik, Modeling and experimental analysis of the aluminium alloy fatigue damage in the case of bending - torsion loading. Procedia Engineering 48, 599-606 (2012)

13. P. Krawiec, G. Domek, J. Adamiec, K. Waluś, Ł. Warguła, The proposal of estimation method of mating between pulleys and cogbelt,55th International Scientific Conference on Experimental Stress Analysis 2017 - EAN 2017, May 30th - June 1st, 2017, Nový Smokovec, Slovakia. Book of abstracts / red. T. Kula, P. Frankovsky, R. Hunady, J. Bocko, F. Trebuna, J. Kostka (2017)

14. D. Wojtkowiak, K. Talaśka, I. Malujda, G. Domek, Estimation of the perforation force for polymer composite conveyor belts taking into consideration the shape of the piercing punch. The International Journal of Advanced Manufacturing Technology https://doi.org/10.1007/s00170-018-2381-3 (2018)

15. K. Talaśka, D. Wojtkowiak, Modelling a mechanical properties of the multilayer composite materials with the polyamide core. MATEC Web of Conferences 157: 02052 (2018)

16. D. Wojtkowiak, K. Talaśka, I. Malujda, G. Domek, Analysis of the influence of the cutting edge geometry on parameters of the perforation process for conveyor and transmission belts. MATEC Web of Conferences 157: 01022 (2018) 